\title{
Factors associated to High School Students Dropout in Mala- kand District Pakistan
}

\author{
Muhammad Asif ${ }^{1, *}$, Muhammad Hayat ${ }^{1}$, Sabir Khan ${ }^{2}$
}

1 Department of Statistics, University of Malakand, Lower Dir, Pakistan

2 Universidade Estadual Paulista “Júlio de Mesquita Filho" (UNESP), Faculdade de Ciências Letras, Programa de Pós-graduação em Educação Escolar - Araraquara (SP), Brasi

* Correspondence: m.asif@uom.edu.pk ; Tel.: +92-301-8996009

\begin{abstract}
Academic failure, low attendance, financial difficulties, and mental illness are some of the major reasons most students drop out of high schools. We investigated how high school dropout risk is affected by socioeconomic, demographic, and institutional characteristics. Therefore, research design is composed of a literature review, Questionnaire surveys by interviewing each student. Besides, the analysis and statistical modelling, the Logistic Regression method was used. The results show that academic performance, job, lack of interest and low learning ability were the significant individual characteristics that affect the high school dropout. Moreover, parental characteristics, including financial condition, lack of awareness, and education, are significant factors associated with high school dropout rates. Some other related factors, such as adaptability and influence of the peer groups, abandoning school by siblings, and extra responsibility at home and a joint family system, are also some notable factors that significantly affect the dropout rate in schools Malakand District of KP province. This research study delivered the results that contribute to the literature in education to identify different factors like student's own, parental, institutional, and household characteristics, which affect a student being a dropout from high school in Malakand district Pakistan.
\end{abstract}

Keywords: Statistical Modelling; Education; Public Sector

\section{Introduction}

Throughout the world, high school students confront complex experiences that influence their decision to stay in high school. The Dropout phenomenon has emerged as one of the undeniable social problems even in the present modern times, resulting in economic and social losses. In addition, drastic mental health consequences for children, families and society as a whole. However, its seriousness varies to culture and countries (Reddy \& Sinha, 2010).

According to the latest UNESCO Institute for Statistics (UIS) data (http://uis.unesco.org/en/topic/out-school-children-and-youth), approximately 59.1 million children of the age of primary school-going children are unable to enroll in school. Most of them belong to sub-Saharan Africa, which is approximately 32.2 million, followed by Southern Asia, with almost 12.5 million. The report also discusses that many children are enrolled in school, but were dropped out soon. The situation is particularly alarming in sub-Saharan Africa, with the highest rate $(18.8 \%)$ of exclusion.

The issue of school dropout is more severe in low-income countries as compared to the upper-middle and high-income countries. For instance, according to the UIS data as of available in September 2019, the initial out-of-school rate in low-income countries is $18.5 \%$, which is considerably higher than the dropout rate (1.7\%) of high-income countries. Likewise, high school drop rates are $38.5 \%$ and $2.5 \%$ in low and high-income countries, respectively. The same report argued that there is an interaction effect of income level and gender on the dropout. It is reported that female in low-income countries is more likely to be a dropout. 
However, male's probability of school dropout is higher in the high-income countries as compared to the female.

In Pakistan, efforts are being made in developments in education. According to UNESCO's latest report, Pakistan's literacy rate is 55 percent and stands at 160th position in the world. Further, in the Khyber Pakhtunkhwa province, the literacy rate is estimated as 49 percent that is less than the overall literacy rate of the country. Further, the United Nations Global Education Monitoring 2016 reported that Pakistan is missing its education targets with much of the world countries to achieve their targets by more than half a century. In the same report, it is highlighted that Pakistan is struggling towards the achievement of its target with 5.6 million children out of primary school, which is a considerably high number of children out of school.

Khyber Pakhtunkhwa (KP), located in the northwestern region of Pakistan, is one of the five administrative provinces of Pakistan by GDP of 27.39 million USD, with a population of 35.53 million according to 2017 census. According to the Alif Ailaan - a nonprofit organization working in the field of education - mentioned in their 2017 report that at the primary level, KP leads the provision of infrastructure as compared to other provinces of Pakistan. However, on the education score, KP is behind the Punjab province, Islamabad Capital Territory, and Gilgit Baltistan. The organization Alif Ailaan ended on August 31st, 2018 (https://www.alifailaan.pk/).

Some studies, for example, Rashid and Awan (2019) and Mughal and Aldridge (2017) have been conducted to investigate and describe predictors that influence school dropout from various perspectives; including, demographic and socioeconomic variables. The risk of a child dropping out of school is affected by several interrelated variables like family background, students' attitude towards study, and experience in school. In Pakistan, various studies, for instance, (Gul \& Arshad, 2013; Hussain, Salfi, \& Mahmood, 2011; Muhammad \& Muhammad, 2011; Zarif, 2012), showed that poverty, parents'education, lack of interest, parent's occupation, part-time work, security, parent's preference of religious education over schooling, distance to school, lacking in facilities, and teachers behavior are the main factors that cause a student to leave the school even before the completion of high school certification. However, by analyzing the geographic concentration index, it is evident that these factors may vary concerning the geographical region. Similarly, Burrus and Roberts (2012) conducted a study in the United States testifies that financial condition, ethnicity (minority group), gender, age, poor attendance, poor grades, lack of engagement with school, and parents involvement are the key predictors of an individual to dropout from school.

Similarly, Latif, Choudhary, and Hammayun (2015) reported that the dropout issue indirectly affects the socioeconomic outcomes of a country. They reported by a comparative analysis of the developed and developing countries that early marriages, security problems, lack of basic facilities in schools, and inability to afford school expenditure - due to families' weak financial position - are some of the significant causes of school dropout. Added to this, Muhammad and Muhammad (2011), Balfanz and Legters (2004), Chinyoka (2014), and Gouda and Sekher (2014) identified poverty as the leading cause of school dropout in developing countries. Specifically, Muhammad and Muhammad (2011) reported that poverty, parent's illiteracy and the lack of awareness, child labor, corporal punishment, lack of quality education in public sector, lack of professional competence and commitment in teachers, quality of curriculum and textbook, lack of physical facilities and infrastructure, lack of supervision and monitoring and lack of political are the major reasons for drop out from high school. Chinyoka (2014) concluded that poverty, child labor, parents' lack of interest, the influence of peer, drug abuse, malnutrition, and poor health and self-lack of interest are the major factors influencing school dropout. Recently, Murphy-Graham et al. (2021) used mixed methods longitudinal data to examine patterns of dropout among a cohort of rural Honduran youth. They reported that dropout is a major problem, especially during transition years and during the first year of upper secondary education. Bui et al. (2020) examined the effect of land fragmentation on child outcomes. They reported that there is invers significant relationship between land fragmentation and child school dropout in the Vietnam. 
There are few studies available in literature where the logistic regression was used to examine the influence of the factors on the dropout. For instance, Gouda and Sekher (2014) reported the influence of household and parental characteristics on dropout by applying logistic regression. They further reported that parental characteristics play an essential role in determining school education. The dropout among children of illiterate parents was four times higher than that of literate parents. Likewise, Franklin and Trouard (2014) used logistic regression for finding risk factors associated with dropout. They showed that age and gender are the strongest predictors of dropout.

School dropout is a complex problem; therefore, its causes cannot merely be identifiable. A dropout is not a single event but can be considered a process related to the social, cultural, and environmental situation (DePaoli, Balfanz, Atwell, \& Bridgeland, 2018; Ullah $\&$ Khan, 2018). The purpose of this study is to identify factors through statistical modeling of dropout students in high schools of District Malakand of KP Province, Pakistan, concerning student's own, parents, school, and household characteristics. In this connection, to the best of our knowledge, no study has been conducted that indicates the main factors that lead to dropout in government schools at the District Malakand. This research aims to study the factors causing drop out in government schools. Knowing the factors affecting the school dropout and its geographical and demographic characteristics is crucial to recognize highrisk groups and to set appropriate strategies and management to deal with (Mughal, 2018; Xuepei, Jinshan, \& Zhang, 2019). In this paper, we investigated how the individual, parental, household, and institutional characteristics affect the school dropout using sophisticated statistical methodologies.

The introduction should briefly place the study in a broad context and highlight why it is important. It should define the purpose of the work and its significance. The current state of the research field should be carefully reviewed and key publications cited. Please highlight controversial and diverging hypotheses when necessary. Finally, briefly mention the main aim of the work and highlight the principal conclusions. As far as possible, please keep the introduction comprehensible to scientists outside your particular field of research. All the references mentioned in the text should be cited in the "Author-Date" format-e.g., (Baranwal and Munteanu [1921] 1955), (Berry and Smith 1999), (Cojocaru et al. 1999) or Driver et al. (2000). See the end of the document for further details on references.

\section{Results and Discussion}

In this section, the results and discussion will point to the factors contributing to the dropout in high school of District Malakand based on the random sample taken from 422 students registered in the year 2012. In our data, a total of 127 (30\%) students were dropped out of school. Among the measurement of causative variables of interest, students were also asked regarding the reasons for leaving school. Most of the dropout students (47\%) responded that they had 'low learning ability,' followed by poverty (14\%), repeating failure $(12 \%)$, teachers' rude behavior (5\%), unable to go school regularly $(5 \%)$, interest to get vocational training $(4 \%)$, health issues $(4 \%)$, parents death $(3 \%)$, parents unwilling to educate their children $(2 \%)$, prefer to get religious education ( $2 \%)$, adoption issue $(1 \%)$, and interest to go abroad for labor-work (1\%). In the following sub-sections, we elaborate on various causes, effects, and individual characteristics in detail.

\subsection{The Effect of Indiviual Characteristics}

Regarding the best subset of covariates relaed to the student's characteristics, which may be considered a significant predictor of the student dropout are: age, poor academic performance, considering job more relaxed, and attention deficiency have a positive relationship with the probability of the dropout. In other words, increasing the value of these covariates increases the chances, while regular offering Salat (prayers) and recitation of the Quran reduces the chances of a student's dropout from high school. The estimated model parameters, along with standard errors, the test of significance (P-values) and oddratios are given in Table- 1 below. The results show a strong association of these covariates with variable dropout as the Neglekerke's $R^{2}$ is $90.8 \%$. 
Table 1. Logistic Model fit with best subset of covariates related to the student's own characteristics using stepwise model selection approach.

\begin{tabular}{|c|c|c|c|c|}
\hline Variable & Coefficient & Std. Error & P-value & Odds Ratio \\
\hline Constant & -10.785 & 2.942 & 0.000 & 0.000 \\
\hline Age & 0.443 & 0.225 & 0.049 & 1.557 \\
\hline Poor Academic performance & 0.719 & 0.253 & 0.004 & 2.052 \\
\hline Job is relaxed than school & 1.819 & 0.433 & 0.000 & 6.168 \\
\hline Deficiency in attention and memory & 0.537 & 0.201 & 0.007 & 1.711 \\
\hline Reciting holy Quran (hours) & -0.387 & 0.290 & 0.183 & 0.679 \\
\hline Prayers (worship-score) & -0.182 & 0.117 & 0.119 & 0.834 \\
\hline Study at home (hours) & -0.724 & 0.497 & 0.145 & 0.485 \\
\hline
\end{tabular}

Age is recorded in years; a unit increase in age at the time of registration increases the odds of being dropout by approximately $56 \%$. Similarly, an hour increase in a study at home reduces the odds of being dropout by more than half. Further, a unit increase in worship score reduces the odds of being dropout by $16.6 \%$, and an hour difference in the daily recitation of the Qur'an reduces the odds of being dropout by $32 \%$. This effect may be the reason that children are in control of their parents. The reason might be that religious affiliation has a strong relationship with discipline. Moreover, it may be that parents of such students have sharply observed and look after their children. Moreover, most of the parents want their children to be regular in religious practices in the Malakand region.

To demonstrate visually the relationship between the probability of 'dropout' and quantitative covariates (age, hours of reciting the Qur'an, hours of study, and worshipscore) the logistic models with single covariate were fitted. Figure 1 demonstrates the relationship between the probability of a student's dropout and age graphically.

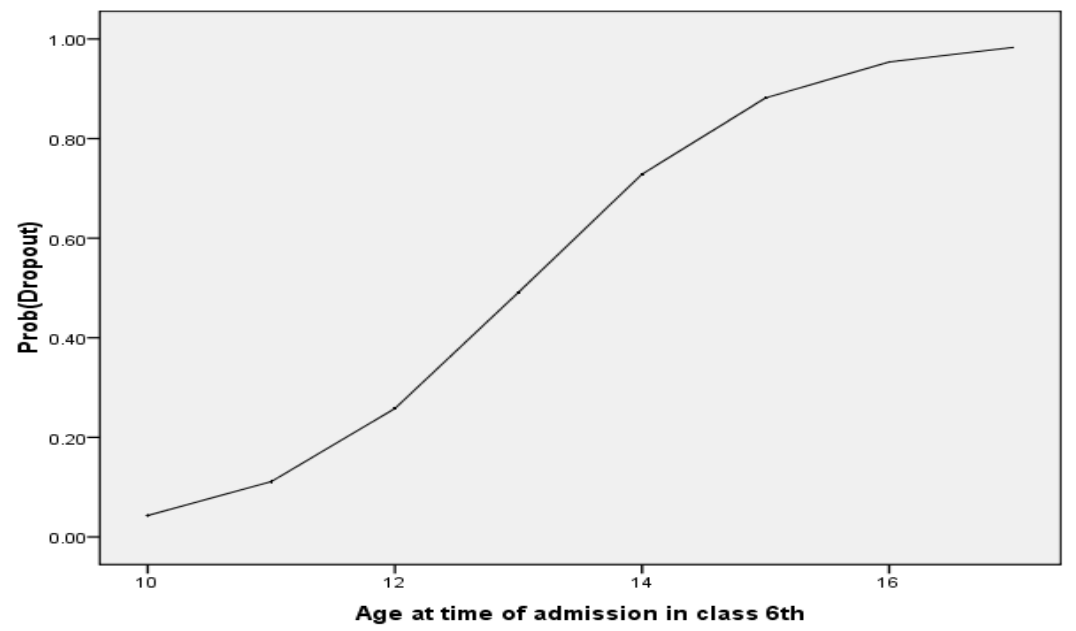

Figure 1. Relationship between the probability of the 'dropout' and covariate age using Logistic Regression with response variable 'dropout' and single covariate 'age'.

\subsection{The Effect of Parental Characteristics}

The results indicate that parental characteristics play a vital role in the education of their children. For instance, financial stability, parents-education, awareness about the importance of education, and small family size reduce the risk of school dropout. In the final 
best-selected model, the covariates poverty, parents-unawareness, father-education, mother-education, family-size, parents-prefer-vocational-training were the subset of covariates related to the parental characteristics were included. The model fits the results provided in the Table-2 below. Though reasonably strong, the strength of association between covariates and response variables, however, as compared to the student's own characteristics, the strength of the association is low as the value of $R^{2}$ was $64.6 \%$.

Table 2. Logistic Model fit with best subset of covariates related to the student's parental characteristics using stepwise model selection approach.

\begin{tabular}{lllll}
\hline Variable & Coefficient & Std. Error & P-value & Odds Ratios \\
\hline Constant & -2.741 & 0.447 & 0.000 & 0.065 \\
Poverty (binary) & 0.357 & 0.126 & 0.005 & 1.429 \\
Unawareness & 0.710 & 0.094 & 0.000 & 2.035 \\
Vocational training preference & 2.774 & 0.818 & 0.001 & 16.029 \\
Father's education (years) & -0.124 & 0.035 & 0.000 & 0.883 \\
Mother's education (years) & -0.402 & 0.203 & 0.048 & 0.669 \\
Family size & 0.052 & 0.035 & 0.134 & 1.054 \\
\hline
\end{tabular}

AIC $=365.136, \quad$ Nagelkerke $R 2=64.6 \%$ and $-2 L L=349.136$

The binary variable 'poverty' takes value 1 (if the parents were unable/challenging to pay the expenditures of the child's education) and 0 (otherwise). The variables "unawareness" and "vocational training preference" were recorded on a Likert scale (1-Strongly disagree, 5-Strongly agree). The variables' parent's education' was recorded in total years of attaining school/college/university.

The results show that the odds of the students belonging to low-income families being dropout are $43 \%$ higher than the odds of the students being dropout belonging to the financially stable family. The effect of poverty is statistically significant as $P<0.001$. Furthermore, a single-year increase in the father's year of education reduces the odds of being dropout of his child by approximately $12 \%$. Similarly, a single-year increase in mother education reduces the odds of dropout by $33 \%$. It can be concluded that although education for both mother and father is essential. However, a mother's education is strongly associated with child dropout as compared to father education. This comparison suggests that more importance should be given to female education in the Malakand region. The odds ratio of each covariate is given in Table- 2 above.

\subsection{The Effect of School Characteristics}

The model fit results showed that the covariates repeated failure, failed to adjust in the school environment, the influence of peer group, and do-not-like-school are the best subset of covariates among the group of possible covariates related to the school characteristics. Furthermore, all these binary covariates in the final model are statistically significant as $\mathrm{P}<0.001$. The strength of association between covariates and dropout students was observed $71.4 \%$ using Nagelkerke' R2. The parameters estimate and inferential statistics are provided in Table-3 below.

Table 3. Logistic Model fit with best subset of covariates related to the student's School characteristics using stepwise model selection approach. 


\begin{tabular}{|c|c|c|c|c|}
\hline Constant & -2.409 & 0.205 & 0.000 & 0.090 \\
\hline Repeated failure & 4.223 & 1.088 & 0.001 & 6.89 \\
\hline Failed to adjust in school & 4.943 & 0.762 & 0.000 & 1.40 \\
\hline Influence of peer group & 3.454 & 0.838 & 0.000 & 3.16 \\
\hline Not like the school & 4.812 & 0.766 & 0.012 & 1.22 \\
\hline$A I C=233.399$ & agelkerk & $1.4 \%$ & $-2 L L=$ & 1.399 \\
\hline
\end{tabular}

The predictor that is strongly associated with the school dropout related to the school characteristics is 'repeated failure.' For example, the odds of the dropout increased by 5.89 times if a student repeatedly failed in the exam. The second most crucial covariate is the 'influence of peer group' with an odds ratio of 3.16. Furthermore, if a student failed to adjust in school, then the odds of being dropout increased by $40 \%$. Moreover, those students who do not like their school have odds of being dropout more than by $22 \%$ as compared to those who like their school.

Related to the teachers' behavior, in our data, approximately all students (dropout and enrolled) liked their teachers. For example, the average value of response value about the likeness (Likert scale) of teachers among dropout students is 4.97 , whereas the mean value of the response of the still enrolled students is 4.29 . The difference is statistically insignificant, showing that all the students like and respect their teachers. However, some of the dropout students have complaints against teachers' rude behavior, and they consider it was the leading cause of their dropout from school. Moreover, from the data, we observed that distance to school is not a reason for dropout, despite some students, for example, some students from Govt. High School (GHS) Malakand, GHS Alladand, and GHS Mekhband had the problem of commuting to school, and hence, causing them to drop out of school.

\subsection{The Effect of Household Characteristics}

The model fit results show that the covariates, for instance, abandoning of school by siblings, and extra responsibility at home (for example, grocery, part-time job), and a student living in a joint family system has a significant effect on the chances of high school dropout. Table-4 illustrated the estimates of the model parameters, the P-values, and Odd ratio.

Table 3. Logistic Model fit with best subset of covariates related to the student's Household characteristics using stepwise model selection approach.

\begin{tabular}{|c|c|c|c|c|}
\hline Variable & Coefficient & Standard Error & P-value & Odds Ratio \\
\hline Constant & -1.907 & 0.294 & 0.000 & 0.148 \\
\hline Number of sisters & 0.104 & 0.071 & 0.142 & 1.110 \\
\hline Siblings abandon school & 0.919 & 0.240 & 0.000 & 2.506 \\
\hline Extra responsibility at home & 0.155 & 0.066 & 0.018 & 1.167 \\
\hline Joint family & -0.728 & 0.358 & 0.042 & 0.483 \\
\hline$A I C=491.04$ & Nagelkerke R2 & $=72.5 \%$ & $2 L L=479.04$ & \\
\hline
\end{tabular}


The most important predictor of the school dropout related to the household characteristics is 'sibling abandoning school' (brother, sister, a cousin living in the same house). That is, the odds of the dropout increased by $151 \%$ if a sibling(s) living in the same house abandon the school. Similarly, 11\% odds of being dropout increased if a student's number of sisters is increased by one. It is noticeable that although the covariate 'number of sisters' included in the final best-selected model. However, the effect is insignificant as the $\mathrm{P}=0.142$. Similarly, the odds of dropout increased by approximately $17 \%$ percent if a student has extra responsibility. Interestingly, that living in the joint family reduces the odds of being dropout by more than half.

\section{Materials and Methods}

To investigate the factors of High Schools Dropout in District Malakand of KP province, the data regarding the students were collected from the schools run and managed by the Government. A sample of 422 high school students was interviewed in November-2016 from the total number of 1122 students registered in the year 2012 in Class Six. The sample was selected in two stages; firstly, a random sample of 16 schools was selected from the total 49 schools in the district. Secondly, a random sample of students was selected from each selected school using stratified sampling with proportional allocation technique. For example, in Government Higher Secondary School (GHSS) Khar, 108 students enrolled in class 6 th in the year 2012. However, only 58 students remained enrolled in school until November-2016, while the remaining 50 students left the school during 2012-2016. Hence, the proportion of enrolled and dropout students is $53.7 \%$ and $46.3 \%$, respectively. Therefore, a stratified random sample consisting of 44 students, 23 enrolled and 21 dropout students, was selected in the sample. In a nutshell, primarily, data were obtained from 16 schools of District Malakand. The sample size was determined using the Waled method of Binomial distribution.

Since this work falls under quantitative research, therefore, the data was collected through a structured questionnaire from each student/respondents, which consisted of a set of standardized questions. A well-trained school teacher (graduated in Statistics) was interviewed by asking/explaining the question to each student in the sample. The questionnaire format was in four different parts. The first part consists of questions regarding a student's characteristics and information. The second part comprises questions regarding parental characteristics, occupation, and education; and the third part included school characteristics, school environment and teachers related matters and the fourth part consist of questions relating to household characteristics.

In this study, the respondents' age at the time of the interview ranges from 14 to 21 years old. Ethical approval for the study was obtained from the Department of Statistics, University of Malakand Ethical Committee. The response variable 'Dropout,' a binary variable, takes value one if the student is a dropout and 0 otherwise. As the dependent variable is dichotomous, we used the Generalized Linear Model (GLM) (Nelder \& Wedderburn, 1972) with the logistic link function. Further, step-wise regression with Akaiki Information Criteria (AIC) of (Sakamoto, Ishiguro, \& Kitagawa, 1986) is used for model selection. Model parameters were estimated using the Maximum Likelihood Estimation (MLE) method. The coefficient of determination (R2), proposed by Nagelkerke (1991), was calculated to measure the strength of the association between the response variable (dropout) and covariates.

To measure students' religious tendencies, we defined a variable worship-score. The worship score is determined by whether a student performing the Salat (Obligatory Prayers) at Mosque, home, or do not perform at all. Note that all students in our sample were Muslims. Salat is the essential worship for Muslims, and it is performed regularly according to a fixed schedule five times a day. We settled the value for a single salat is either 0 (if a student does not perform the salat), 1 (if the student offers salat at home), and 2 (if the student offers salat at Mosque). Hence, the salat score ranges from 0 (if a student does not offer salat in a day) or to 10 (if a student offers salat five times a day in the Mosque).

\section{Conclusions}


This paper has focused on the factors that influence the dropout ratio in High schools of Malakand District of Khyber Pakhtunkhwa province before they reach Class-X during the period 2012-2016. From the results, it is observed that age, poor academic performance, a tendency towards a job, and deficiency in attention and memory are the significant individual factors contributing to the dropout ratio. Moreover, religious tendencies, reciting the Holy Quran, regularly offering prayers, and study at home are included in the final best-selected model. However, these effects are statistically insignificant. Regarding the effect of parental characteristics, poverty, unawareness about the importance of education, and parents' education significantly affects the risk of dropout. Further, the covariate family size was included among the best subset of covariates in the model; however, the effect of family size was observed statistically insignificant.

Regarding the effect of school characteristics, repeated failure in class, adaptability, and influence of the peer group are the significant factors that affect the probability of the dropout. Moreover, the results show that abandoning school by siblings, extra responsibility at home have a positive effect on the dropout, whereas living in a joint family system has a negative effect. The findings of this study might be helpful for policymakers in making future strategies and policies to prevent dropout of students in District Malakand. It is essential to mention that our research is not without limitations. We assessed some critical factors contributing to dropout, but some other social factors should also be included in the model, for example, the gender aspect in future research. In the future, we are committed to extending this study to private schools with more associated parameters, which is an area of considerable interest in the present privatization scenario of the country.

Author Contributions: Supervision, conceptualization, methodology, and writing original draft by M.A.; resources, data curation, software, validation, visualization and formal analysis by M.H.; investigation, data curation, and writing - review and editing by S.K. All authors have read and agreed to the published version of the manuscript.

Funding: This research received no external funding

Data Availability Statement: The data used in this research are fully available without any restriction.

Acknowledgments: We are thankful to the Dr. Iqbal Ahmad, Chairman Department of Education, for his comments that helped to improve the quality of this article.

Conflicts of Interest: The authors declare no conflict of interest.

\section{References}

1. Bui, Q. N., Hoang, T. X., Nguyen, M. K., \& Nguyen, T. T. (2020). Land fragmentation, women empowerment and school dropout of children in Vietnam. Land Use Policy, 97, 104749. https://doi.org/10.1016/j.landusepol.2020.104749

2. Balfanz, R., \& Legters, N. (2004). Locating the Dropout Crisis. Which High Schools Produce the Nation's Dropouts? Where Are They Located? Who Attends Them? Report 70. Center for Research on the Education of Students Placed at Risk CRESPAR.

3. Burrus, J., \& Roberts, R. D. (2012). Dropping out of high school: Prevalence, risk factors, and remediation strategies. R \& D Connections, 18(2), 1-9.

4. Chinyoka, K. (2014). Causes of school dropout among ordinary level learners in a resettlement area in Masvingo, Zimbabwe. Journal of Emerging Trends in Educational Research and Policy Studies, 5(3), 294-300.

5. DePaoli, J., Balfanz, R., Atwell, M., \& Bridgeland, J. (2018). Building a grad nation: progress and challenge in raising high school graduation rates. Annual update 2018. Civic Enterprises. In.

6. Franklin, B. J., \& Trouard, S. B. (2014). An analysis of dropout predictors within a state high school graduation panel. Schooling, $5,1-8$.

7. Gouda, S., \& Sekher, T. (2014). Factors leading to school dropouts in India: An analysis of national family health survey-3 data. IOSR Journal of Research \& Method in Education, 4(6), 75-83.

8. Gul, R., \& Arshad, A. (2013). Causes of Dropout Rate in Government High Schools (Male). American international journal of research in humanities, arts and social sciences, 3(1), 120-125.

9. Hussain, A., Salfi, N., \& Mahmood, T. (2011). Causes of students' dropout at primary level in Pakistan: An empirical study. International journal of humanities and social science, 1(12), 143-151. 
10. Latif, A., Choudhary, A., \& Hammayun, A. (2015). Economic effects of student dropouts: A comparative study. Journal of global economics.

11. Mughal, A. W. (2018). Investigating the issue of out-of-school children in rural Pakistan: implications for policymakers. Loughborough University,

12. Mughal, A. W., \& Aldridge, J. (2017). Head Teachers' Perspectives on School Drop-Out in Secondary Schools in Rural Punjab, Pakistan. Educational Studies, 53(4), 359-376.

13. Murphy-Graham, E., Pacheco Montoya, D., Cohen, A. K., \& Valencia Lopez, E. (2021). Examining school dropout among rural youth in Honduras: Evidence from a mixed-methods longitudinal study. International Journal of Educational Development, 82, 102329. https://doi.org/10.1016/j.ijedudev.2020.102329

14. Muhammad, F., \& Muhammad, A. (2011). Determining the factors influencing the drop out in Government primary schools of Karachi. Middle-East Journal of Scientific Research, 7(3), 417-420.

15. Nagelkerke, N. J. (1991). A note on a general definition of the coefficient of determination. Biometrika, 78(3), 691-692.

16. Nelder, J. A., \& Wedderburn, R. W. (1972). Generalized linear models. Journal of the Royal Statistical Society: Series A (General), 135(3), 370-384.

17. Rashid, T., \& Awan, A. G. (2019). Causes of high dropout ratio at graduate level: A case study of District Vehari-Pakistan. Global Journal of Management, Social Sciences and Humanities, 5(1), 91-115.

18. Reddy, A. N., \& Sinha, S. (2010). School Dropouts or Pushouts? Overcoming Barriers for the Right to Education. CREATE Pathways to Access. Research Monograph No. 40: ERIC.

19. Sakamoto, Y., Ishiguro, M., \& Kitagawa, G. (1986). Akaike information criterion statistics. Dordrecht, The Netherlands: D. Reidel, 81.

20. Ullah, N., \& Khan, M. (2018). The General Causes of Students' Dropout at Primary School. Journal of Sociology, 2(1), 35-49.

21. Xuepei, Z., Jinshan, Y., \& Zhang, T. (2019). A Comparative Study of Primary Education in China and Pakistan-1947-2018. Journal of the Research Society of Pakistan, 56(1), 169.

22. Zarif, T. (2012). Reasons of high dropout rate of students in grades 5-6 at public schools of District Kashmore (Sindh-Pakistan) in 2010-11. Journal of Research \& Reflections in Education (JRRE), 6(2). 